\title{
Association between the A-2518G polymorphism in the monocyte chemoattractant protein-1 gene and insulin resistance and Type 2 diabetes mellitus
}

\author{
E. Simeoni ${ }^{1,2}$ • M. M. Hoffmann ${ }^{3}$ B. R. Winkelmann ${ }^{4}$ J. Ruiz ${ }^{5}$ S. Fleury ${ }^{1,2}$ • B. O. Boehm ${ }^{6}$ W. März ${ }^{7}$ \\ G. Vassalli 1,8 \\ ${ }^{1}$ Department of Cardiology, University Hospital, CHUV-BH10, Lausanne, Switzerland \\ 2 Department of Experimental Surgery, University Hospital, Lausanne, Switzerland \\ ${ }^{3}$ Department of Clinical Chemistry, University Hospital, Freiburg, Germany \\ ${ }^{4}$ Cooperation Unit of Pharmacogenomics/Applied Genomics, University of Heidelberg, Germany \\ ${ }^{5}$ Department of Endocrinology, University Hospital, Lausanne, Switzerland \\ ${ }^{6}$ Division of Endocrinology and Diabetes, Department of Medicine, University Hospital, Ulm, Germany \\ ${ }^{7}$ Department of Clinical Chemistry, University Hospital, Graz, Austria \\ ${ }^{8}$ Institute of Microbiology, University Hospital, Lausanne, Switzerland
}

\begin{abstract}
Aims/hypothesis. The molecular mechanisms of obesity-related insulin resistance are incompletely understood. Macrophages accumulate in adipose tissue of obese individuals. In obesity, monocyte chemoattractant protein-1 (MCP-1), a key chemokine in the process of macrophage accumulation, is overexpressed in adipose tissue. $M C P-1$ is an insulin-responsive gene that continues to respond to exogenous insulin in insulin-resistant adipocytes and mice. MCP-1 decreases insulin-stimulated glucose uptake into adipocytes. The $A-2518 G$ polymorphism in the distal regulatory region of $M C P-1$ may regulate gene expression. The aim of this study was to investigate the impact of this gene polymorphism on insulin resistance.

Methods. We genotyped the Ludwigshafen Risk and Cardiovascular Health (LURIC) cohort $(n=3307)$. Insulin resistance, estimated by homeostasis model assessment, and Type 2 diabetes were diagnosed in 803 and 635 patients respectively.

Results. Univariate analysis revealed that plasma MCP-1 levels were significantly and positively cor-
\end{abstract}

related with WHR $(p=0.011)$, insulin resistance $(p=0.0097)$ and diabetes $(p<0.0001)$. Presence of the $M C P-1 G-2518$ allele was associated with decreased plasma MCP-1 $(p=0.017)$, a decreased prevalence of insulin resistance (odds ratio $[\mathrm{OR}]=0.82,95 \% \mathrm{CI}$ : $0.70-0.97, p=0.021)$ and a decreased prevalence of diabetes (OR=0.80, 95\% CI: 0.67-0.96, $p=0.014)$. In multivariate analysis, the $G$ allele retained statistical significance as a negative predictor of insulin resistance $(\mathrm{OR}=0.78,95 \% \mathrm{CI}: 0.65-0.93, p=0.0060)$ and diabetes $(\mathrm{OR}=0.80,95 \%$ CI: $0.66-0.96$, $p=0.018$ ).

Conclusions/interpretation. In a large cohort of Caucasians, the MCP-1 G-2518 gene variant was significantly and negatively correlated with plasma MCP-1 levels and the prevalence of insulin resistance and Type 2 diabetes. These results add to recent evidence supporting a role for $\mathrm{MCP}-1$ in pathologies associated with hyperinsulinaemia.

Keywords Diabetes Insulin resistance ·

Macrophage $\cdot$ Monocyte chemoattractant protein-1 . Polymorphism
Received: 5 May 2004 / Accepted: 18 June 2004

Published online: 2 September 2004

(C) Springer-Verlag 2004

G. Vassalli (

Department of Cardiology, University Hospital, CHUV-BH10,

1011 Lausanne, Switzerland

E-mail: giuseppe.vassalli@ chuv.hospvd.ch

Tel.: +41-21-3140076, Fax: +41-21-3140013

\section{Introduction}

The molecular mechanisms that link obesity and insulin resistance are incompletely understood $[1,2,3]$. Obesity, insulin resistance and diabetes mellitus share a

Abbreviations: CAD, coronary artery disease $\cdot \mathrm{HOMA}_{\mathrm{IR}}$, homeostasis model assessment of insulin resistance $\cdot$ MCP-1, monocyte chemoattractant protein- $1 \cdot$ MIP- $1 \alpha$, macrophage inflammatory protein- $1 \alpha \cdot \mathrm{NF}-\kappa \mathrm{B}$, nuclear factor- $\kappa \mathrm{B} \cdot \mathrm{PAI}-1$, plasminogen-activator inhibitor-1 
chronic, low-grade inflammatory component $[4,5,6$, 7], as reflected by increased expression of proinflammatory cytokines such as TNF- $\alpha$ [8], IL-6 [9], and monocyte chemoattractant protein-1 (MCP-1) $[6,7,10,11]$. Adipose tissue functions as an endocrine organ that secretes a number of biologically active proteins, including TNF- $\alpha$ [8], IL-6 [6, 12], IL-8 [13], C-reactive protein, inducible nitric oxide synthase [6], TGF- $\beta 1$, plasminogen-activator inhibitor-1 (PAI-1) [14], adiponectin [15], resistin [16], leptin [13, 17], macrophage inflammatory protein-1 $\alpha$ (MIP-1 $\alpha)[7,13]$ and MCP-1 $[6,7$, $10,11,17]$. Obesity alters adipose tissue endocrine function and leads to the increased secretion of proinflammatory cytokines (so-called "adipokines"), hormones and fatty acids $[6,7,10]$. In turn, TNF- $\alpha$, IL-1 $1 \beta$, and other adipokines stimulate MCP-1 production and release by human differentiated adipocytes [13].

MCP-1, which is a member of the chemokine family, plays a key role in the recruitment of monocytes/ macrophages to inflammatory foci [18]. High glucose directly up-regulates $M C P-1$ expression in vascular endothelial cells and monocytes [19, 20]. MCP-1 mRNA is dramatically overexpressed (increased by a factor of seven) in white adipose tissue of genetically obese $(o b / o b)$ mice compared with lean control mice [10]. In these mice, the highest level of MCP-1 expression is in subcutaneous adipose tissue, with the liver showing $<10 \%$ and the kidney and lung showing $1-2 \%$ of the level of MCP-1 expression in adipose tissue [10]. Insulin induces the production and secretion of substantial amounts of MCP-1 in insulin-resistant adipocytes and insulin-resistant obese mice [10]. $M C P-1$ is similar to other genes such as PAI- 1 and $S R E B P-1 c$ in that it continues to respond to exogenous insulin in insulin-resistant states [10, 21]. Moreover, MCP-1 inhibits (by approximately 30\%) insulin-stimulated glucose uptake into mouse adipocytes [10]. Transcriptional profiling experiments have shown that a number of inflammation and macrophage-enriched or specific genes, such as $M C P-1, M I P-1 \alpha, A D A M 8$, $M A C-1, F 4 / 80$ and $C D 68$, are up-regulated in white adipose tissue of mice with genetic or diet-induced obesity [6,7]. Of the 100 genes whose expression was most significantly correlated with body mass, $30 \%$ encoded proteins that are characteristic of macrophages. In human subcutaneous adipose tissue, both BMI and average adipocyte size were significant predictors of macrophage accumulation [6]. In bone marrow transplant experiments in irradiated mice, $85 \%$ of the macrophages that accumulated in adipose tissue after placing the mice on a high-fat diet were of bone marrow origin [6]. In addition, in Csflop/op mice lacking macrophages, the presence of cells expressing the macrophage marker F4/80 in adipose tissue was greatly reduced compared with that in wild-type mice [6]. These findings suggest new models involving macrophage infiltration into adipose tissue in obesity-related insulin resistance.
Genetic differences in chemokine expression may contribute to differences in the severity of inflammatory processes between individuals. Substantial interindividual variability in MCP-1 production in response to proinflammatory cytokines has previously been described [22, 23]. Human $M C P-1$ transcription is under the control of two distinct regions within the 5 '-flanking sequence of the gene. The distal region contains two NF- $\kappa \mathrm{B}$ binding sites and is essential for cytokine-dependent regulation, while the proximal region contains a GC box that may regulate tissuespecific expression [24]. A common $\mathrm{A} \rightarrow \mathrm{G}$ polymorphism located at position -2518 in the distal regulatory region regulates MCP-1 expression. This was demonstrated by transfection experiments in A172 and $293 \mathrm{~T}$ cells using reporter gene constructs containing the distal regulatory region of the $M C P-1$ gene with either variant at position -2518 [22, 25]. Moreover, MCP-1 expression in isolated, cytokine-stimulated human peripheral blood mononuclear cells $[22,25]$ and hepatic cells [26], and plasma MCP-1 levels in patients with lupus nephritis support the assumption that the gene polymorphism regulates MCP-1 expression at the transcriptional level [25]. Case-control gene association studies have reported statistical associations between the polymorphism and lupus nephritis [25], coronary artery disease (CAD) [27] and asthma [28]. The aim of the present study was to test the hypothesis that the $M C P-1$ A-2518G polymorphism influences plasma MCP-1 levels and the risk of developing insulin resistance and Type 2 diabetes.

\section{Subjects and methods}

Study population and clinical definitions. We genotyped the Ludwigshafen Risk and Cardiovascular Health (LURIC) cohort of 3316 individuals who underwent coronary angiography because of chest pain or non-invasive tests consistent with myocardial ischaemia [29]. All individuals were Caucasians born in Germany to parents of German ancestry. Coronary artery disease was defined angiographically by a $\geq 20 \%$ reduction in lumenal diameter in one or more major epicardial coronary arteries or a $10 \%$ to $19 \%$ reduction in three or more (out of 15 ) coronary artery segments. Genetic testing of this cohort was approved by the appropriate institutional ethics committee and informed consent was obtained from the patients. After excluding nine individuals with Type 1 diabetes, the study population included 3307 individuals. Insulin resistance was estimated by homeostasis model assessment $\left(\mathrm{HOMA}_{\mathrm{IR}}\right)$ [30] in the 2798 individuals who were not receiving oral hypoglycaemic drugs or insulin treatment. The threshold for insulin resistance was defined as the 90th percentile of $\mathrm{HOMA}_{\mathrm{IR}}$ distribution in individuals $(n=350)$ with no markers of the metabolic syndrome [30]. Type 2 diabetes was defined according to the new criteria of the American Diabetes Association (ADA) and the provisional criteria of the World Health Organization (WHO) [31, 32, 33]. Unlike in a previous study of the same cohort [34], subjects with a single test showing a high blood glucose level, in the absence of a confirmatory test, were not assigned an unequivocal diabetes status. Older age was defined by the 50th percentile of the study population. 
Assessment of plasma MCP-1 levels. Plasma MCP-1 was measured in a subgroup of 940 consecutive patients (starting from recruitment number 1001) using the Quantikine Human MCP-1 Immunoassay (R\&D Systems, Abingdon, UK). There were no significant differences $(p>0.1)$ between this subgroup and the study population as a whole with respect to insulin resistance or diabetes distribution. Blood samples were collected, processed and stored according to the manufacturer's instructions. The sensitivity of the kit is approximately $0.6 \mathrm{pmol} / \mathrm{l}$, which is well below the lowest concentration measured in the present study $(2.9 \mathrm{pmol} / \mathrm{l})$.

Genotyping. Genotyping of the MCP-1 A-2518G polymorphism was carried out by RFLP-PCR as described previously [22]. Data are incomplete due to missing or equivocal results in five subjects.

Statistical analysis. Data are shown as frequencies in percent (numbers of subjects) or median values (25-75 percentiles). The JMP program (Version 5; SAS Institute, Cary, N.C., USA) was used for statistical analysis. Frequencies were compared by the Cochrane-Armitage trend test. Due to skewed distribution, plasma MCP-1 data were analysed by non-parametric tests (Wilcoxon and Kruskal-Wallis rank-sum tests). The gene counting method estimated allele frequencies, and the chi square test was used to test for deviations of genotype frequencies from Hardy-Weinberg equilibrium. The independent contributions of clinical and genetic characteristics (age, insulin resistance, diabetes, obesity, WHR, HDL cholesterol, triglycerides, hypertension, $\mathrm{CAD}$ and $M C P-1$ polymorphism) to MCP-1 plasma levels (entered as the dependent variable) were assessed by multivariate analysis (standard least square). The independent contributions of the $M C P-1$ polymorphism to insulin resistance and diabetes were determined by nominal logistic analysis, with insulin resistance or diabetes entered as the dependent variable, and age, sex, obesity, hypertension, HDL cholesterol, triglycerides and WHR entered as independent variables. In a subanalysis, diabetes was entered as a three-class-dependent variable (encoded as no diabetes $=0$, non-insulin-treated diabetes $=1$, insulin-treated diabetes $=2$ ). A $p$ value (two-tailed) of less than 0.05 was considered to be statistically significant.

\section{Results}

Clinical characteristics, insulin resistance and diabetes. In total, 29\% (803 of 2798) of individuals who were not on pharmacological oral hypoglycaemic treatment had $\mathrm{HOMA}_{\mathrm{IR}}$ index values higher than or equal to 2.96, indicating insulin resistance. Type 2 diabetes was diagnosed in $20 \%$ (635 of 3205) of subjects. Among the diabetic patients, $25 \%(n=161)$ were on no oral hypoglycaemic drugs, $44 \%(n=278)$ were on oral hypoglycaemic drugs and $31 \%(n=196)$ were on insulin. Coronary angiography showed coronary artery stenoses (lumen reduction $\geq 50 \%$ ) in $69 \%$ of patients, minor lesions (lumen reduction $<50 \%$ ) in $14 \%$ and smooth arteries in $17 \%$. Table 1 shows the clinical characteristics of the study population subdivided according to insulin sensitivity or diabetes status, and the results of univariate analysis of the clinical characteristics in these subsets.

Genotype frequencies. In the population as a whole, the frequencies of the genotypes of the $A-2518 G$ polymorphism were: 1757 (53\%) AA homozygous, 1303 (39\%) $G A$ heterozygous and 242 (7\%) GG homozygous. The genotype frequencies were in Hardy-Weinberg equilibrium in the population as a whole and in cases and controls defined by insulin sensitivity or diabetes status. No differences were found between $G$ allele carriers ( $G A$ or $G G$ genotype) and non-carriers ( $A A$ genotype) with respect to age, sex, obesity, WHR, hypertension, triglycerides or HDL cholesterol between subsets (data not shown).

Associations between plasma MCP-1 levels and clinical and genetic data. In univariate analysis, plasma MCP-1 levels were significantly and positively correlated with age, CAD and markers of the metabolic syndrome (insulin resistance, Type 2 diabetes, hypertension, obesity, WHR, high triglycerides and low HDL cholesterol; Table 2). In addition, plasma

Table 1. Associations between clinical characteristics and insulin resistance and diabetes

\begin{tabular}{|c|c|c|c|c|c|c|}
\hline Characteristic & $\begin{array}{l}\text { Insulin-sensitive } \\
\text { patients } \\
(n=1995)^{\mathrm{a}}\end{array}$ & $\begin{array}{l}\text { Insulin-resistant } \\
\text { patients }{ }^{\mathrm{k}} \\
(n=803)^{\mathrm{b}}\end{array}$ & $p$ value & $\begin{array}{l}\text { Non-diabetic } \\
\text { patients } \\
(n=2570)^{c}\end{array}$ & $\begin{array}{l}\text { Diabetic } \\
\text { patients } \\
(n=635)^{\mathrm{d}}\end{array}$ & $p$ value \\
\hline Sex (males) & $68.7(1370)$ & $74.2(596)$ & 0.0037 & $70.3(1806)$ & $67.7(430)$ & 0.21 \\
\hline Arterial hypertension ${ }^{f}$ & $53.6(1070)$ & $64.9(521)$ & $<0.0001$ & $54.6(1404)$ & $72.3(459)$ & $<0.0001$ \\
\hline High triglycerides $\mathrm{g}$ & $39.2(782)$ & $60.8(488)$ & $<0.0001$ & $42.8(1100)$ & $61.4(389)$ & $<0.0001$ \\
\hline WHRj & $72.9(1433)$ & $81.3(644)$ & $<0.0001$ & $74.1(1875)$ & $83.9(533)$ & $<0.0001$ \\
\hline
\end{tabular}

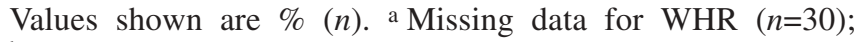
$\mathrm{b}$ missing data for triglycerides $(n=1)$, HDL cholesterol $(n=1)$ and WHR $(n=11)$; ${ }^{\mathrm{c}}$ missing data for HDL cholesterol $(n=1)$ and WHR $(n=41)$; ${ }^{\mathrm{d}}$ missing data for triglycerides $(n=1)$; ${ }^{\mathrm{e}}$ older age, $\geq 62.7$ years; ${ }^{\mathrm{f}}$ hypertension, supine systolic blood pressure $\geq 140 \mathrm{~mm} \mathrm{Hg}$ and/or diastolic pressure $\geq 90 \mathrm{~mm} \mathrm{Hg}$; g high triglycerides, $\geq 150 \mathrm{mg} / \mathrm{ml}$; h low HDL cholesterol, $<35 \mathrm{mg} / \mathrm{ml}$ in males and $<45 \mathrm{mg} / \mathrm{ml}$ in females; ${ }^{i}$ obesity, BMI $\geq 30 \mathrm{~kg} / \mathrm{m}^{2}$; $\mathrm{j}$ high WHR, $>0.95$ in males and $>0.80$ in females; $\mathrm{k}$ insulin resistance, $\mathrm{HOMA}_{\mathrm{IR}}$ index $\geq 2.96$ 
Table 2. Associations between plasma MCP-1 levels and clinical characteristics

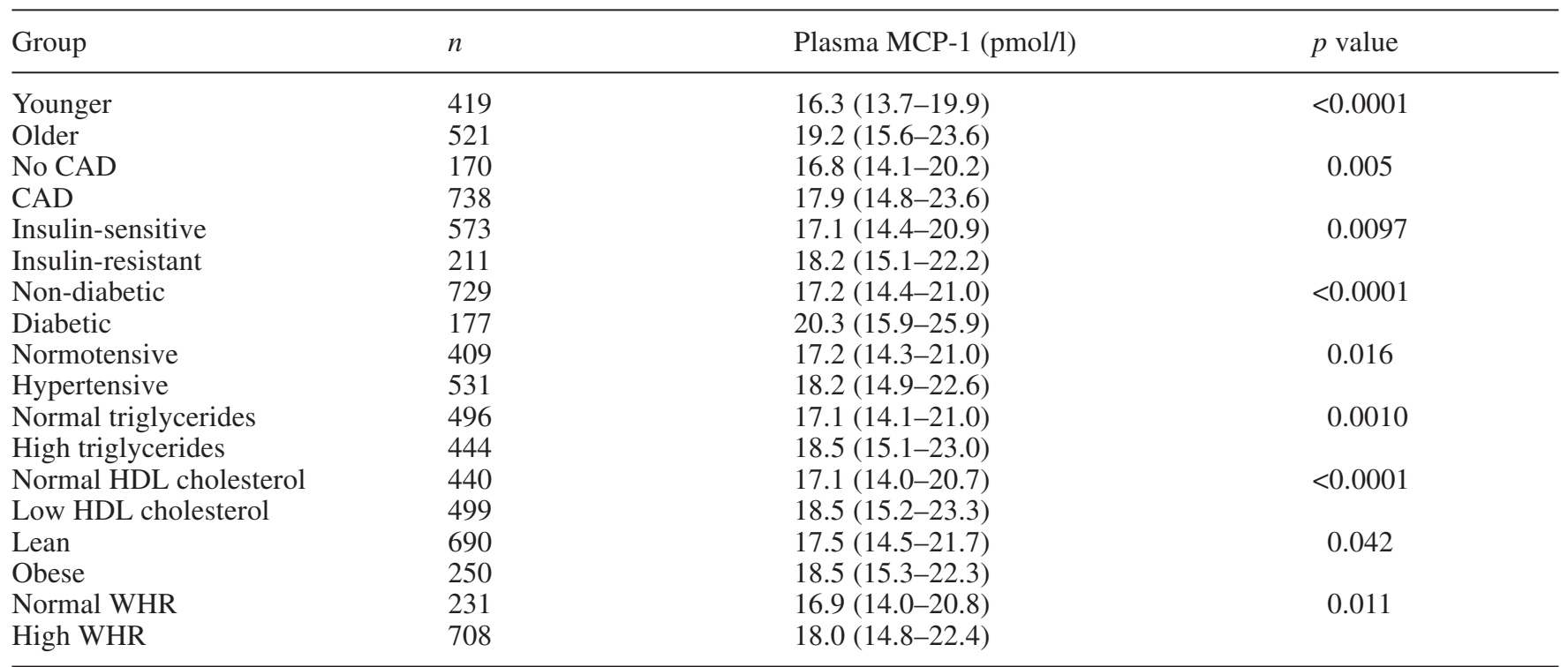

Values are medians (25-75 percentiles). Missing data for CAD ( $n=32)$, diabetes status (absence of confirmatory test; $n=34)$, HDL cholesterol $(n=1)$ and WHR $(n=1)$

Table 3. Associations between the $M C P-1$ polymorphism and plasma MCP-1 levels, insulin resistance and diabetes

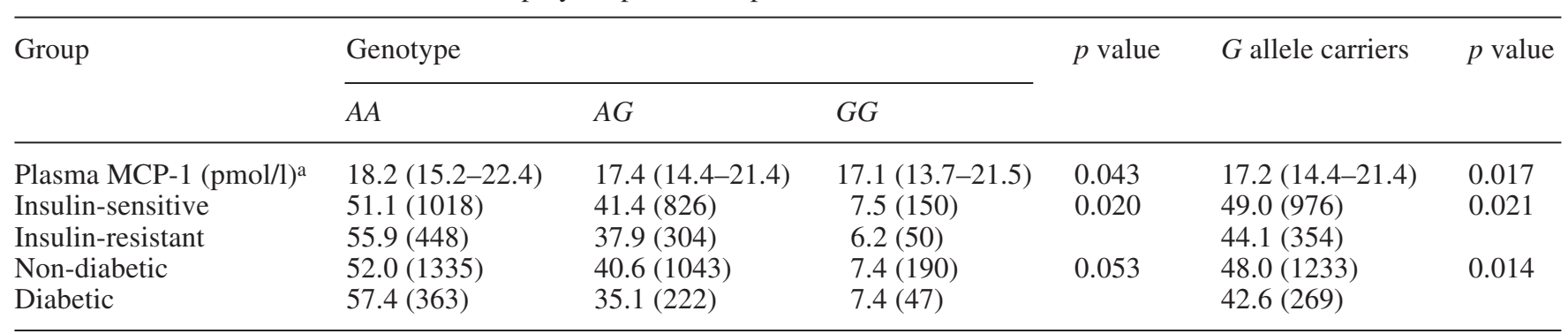

Values are $\%(n)$ unless otherwise indicated. ${ }^{a}$ Values are medians (25-75 percentiles)

MCP-1 levels were negatively correlated with the presence of the $G$ allele at position -2518 of $M C P-1$ ( $p=0.043$ and $p=0.017$ for genotype and $G$ allele carrier frequencies respectively; Table 3 ). In multivariate analysis, age and HDL cholesterol remained associated with plasma MCP- $1 \quad(p<0.0001$ and $p=0.002$ respectively), with a trend towards statistical significance for the $M C P-1$ polymorphism $(p=0.06)$, whereas all other associations lost statistical significance $(p>0.1)$.

Association between the MCP-1 A-2518G polymorphism and insulin resistance. The frequencies of the $M C P-1$ genotypes were significantly different between insulin-sensitive and insulin-resistant subjects $(p=0.020)$, as were the frequencies of $G$ allele carriers $(p=0.021$; Table 3). In multivariate analysis (Table 4), both genotype and $G$ allele carrier frequencies retained significant associations with insulin resistance $\left(\chi^{2}=7.56, p=0.023\right.$ and $\chi^{2}=7.55, p=0.006$ respectively).
Association between the MCP-1 A-2518G polymorphism and Type 2 diabetes. Presence of the $G$ allele was associated with a decreased prevalence of Type 2 diabetes ( $p=0.014$; Table 3 ). In multivariate analysis, genotype and $G$ allele carrier frequencies were significantly associated with a decreased prevalence of diabetes $\left(\chi^{2}=7.03, p=0.030\right.$ and $\chi^{2}=5.62, p=0.018$, respectively; Table 5). The decrease in the frequency of $G$ allele carriers was more marked in the subgroup of insulin-treated patients than in the subgroup of non-insulin-treated diabetic patients $(39 \%$ and $44 \%$ respectively, vs $48 \%$ in non-diabetic individuals; $\chi^{2}=7.76$, $p=0.021$ by three-class analysis).

Association between the MCP-1 A-2518G polymorphism and obesity-related insulin resistance. A subgroup analysis revealed that, among obese patients, the insulin-sensitive subgroup contained a higher proportion of $M C P-1 G-2518$ carriers than the insulinresistant subgroup (52.5\% vs $43.9 \%$; $p=0.04$ ). Similarly, obese individuals who did not develop Type 2 dia- 
Table 4. Nominal logistic fit, with insulin resistance entered as the dependent variable

\begin{tabular}{|c|c|c|c|c|c|c|c|c|c|}
\hline \multirow[b]{2}{*}{ Source of variation } & \multicolumn{4}{|c|}{ Genotype analysis } & \multicolumn{5}{|c|}{$G$ allele carriers analysis } \\
\hline & $d f$ & $r^{2}$ & $\chi^{2}$ & $p$ value & $d f$ & $r^{2}$ & $\chi^{2}$ & $p$ value & OR $(95 \% \mathrm{CI})$ \\
\hline All variables & 9 & 0.09 & 301.28 & $<0.0001$ & 8 & 0.09 & 301.27 & $<0.0001$ & \\
\hline Older age & 1 & & 7.60 & 0.0058 & 1 & & 7.62 & 0.0058 & $1.29(1.08-1.54)$ \\
\hline Male sex & 1 & & 17.77 & $<0.0001$ & 1 & & 17.83 & $<0.0001$ & $1.56(1.27-1.92)$ \\
\hline Hypertension & 1 & & 5.52 & 0.019 & 1 & & 5.51 & 0.019 & $1.25(1.04-1.50)$ \\
\hline High triglycerides & 1 & & 52.99 & $<0.0001$ & 1 & & 53.06 & $<0.0001$ & $1.96(1.64-2.35)$ \\
\hline Low HDL cholesterol & 1 & & 21.99 & $<0.0001$ & 1 & & 21.97 & $<0.0001$ & $1.55(1.29-1.86)$ \\
\hline Obesity & 1 & & 116.19 & $<0.0001$ & 1 & & 116.19 & $<0.0001$ & $3.00(2.45-3.66)$ \\
\hline High WHR & 1 & & 5.01 & 0.025 & 1 & & 5.02 & 0.025 & $1.29(1.03-1.62)$ \\
\hline $\begin{array}{c}M C P-1 A-2518 G \\
\text { polymorphism }\end{array}$ & 2 & & 7.56 & 0.023 & 1 & & 7.55 & 0.0060 & $0.78(0.65-0.93)$ \\
\hline
\end{tabular}

In this multivariate model, $n=2753$ due to incomplete data. $d f: 2$ for genotype three-class analysis (encoded as $A A=0, A G=1$, $G G=2$ ), 1 for $G$ allele carrier two-class analysis (encoded as $A A=0, A G+G G=1$ ). OR, odds ratio

Table 5. Nominal logistic fit, with Type 2 diabetes entered as the dependent variable

\begin{tabular}{|c|c|c|c|c|c|c|c|c|c|}
\hline \multirow[b]{2}{*}{ Source of variation } & \multicolumn{4}{|c|}{ Genotype analysis } & \multicolumn{5}{|c|}{$G$ allele carriers analysis } \\
\hline & $d f$ & $r^{2}$ & $\chi^{2}$ & $p$ value & $d f$ & $r^{2}$ & $\chi^{2}$ & $p$ value & OR $(95 \% \mathrm{CI})$ \\
\hline Older age & 1 & & 88.33 & $<0.0001$ & 1 & & 88.81 & $<0.0001$ & $2.60(2.13-3.17)$ \\
\hline Male sex & 1 & & 2.08 & 0.15 & 1 & & 2.15 & 0.14 & $1.17(0.95-1.44)$ \\
\hline Hypertension & 1 & & 26.50 & $<0.0001$ & 1 & & 26.45 & $<0.0001$ & $1.70(1.39-2.08)$ \\
\hline Obesity & 1 & & 21.69 & $<0.0001$ & 1 & & 21.49 & $<0.0001$ & $1.63(1.32-2.00)$ \\
\hline High WHR & 1 & & 5.13 & 0.024 & 1 & & 5.08 & 0.024 & $1.33(1.03-1.71)$ \\
\hline $\begin{array}{c}M C P-1 A-2518 G \\
\text { polymorphism }\end{array}$ & 2 & & 7.03 & 0.030 & 1 & & 5.62 & 0.018 & $0.80(0.66-0.96)$ \\
\hline
\end{tabular}

In this multivariate model, $n=3247$ due to incomplete data. $d f: 2$ for genotype three-class analysis (encoded as $A A=0, A G=1$, $G G=2$ ), 1 for $G$ allele carrier two-class analysis (encoded as $A A=0, A G+G G=1$ ). OR, odds ratio

betes were more likely to be $G$ allele carriers than those who became diabetic ( $48.5 \%$ vs $40.5 \% ; p=0.06$ ). Plasma MCP-1 levels were significantly increased in obese diabetic patients compared with those in obese non-diabetic patients (21.4 vs $17.6 \mathrm{pmol} / \mathrm{l} ; p<0.05)$.

\section{Discussion}

There is increasing evidence that MCP-1, a potent chemoattractant of monocytes/macrophages, participates in metabolic activities that involve regulation of adipose tissue functions, inhibition of insulin-stimulated glucose uptake into adipocytes [10] and accumulation of macrophages in adipose tissue in obese humans [6]. In search of genetic factors that affect insulin resistance, we investigated the role of the common MCP-1 A-2518G polymorphism, which may regulate MCP-1 expression at the transcriptional level [22, 25, 26]. In a large cohort of Caucasians with a high prevalence of cardiovascular risk factors, we found decreased plasma MCP-1 levels and a decreased preva- lence of insulin resistance and Type 2 diabetes in carriers of the $G$ allele compared with subjects homozygous for the frequent $A$ allele. A protective role for this genetic variant is supported by the finding that, among obese patients, the frequency of $G$ allele carriers was increased in those with preserved insulin sensitivity. In multivariate analysis, the $G$ allele remained significantly and negatively correlated with insulin resistance and diabetes after correction for risk factors identified by univariate analysis (including CAD). The decrease in $G$ allele frequency was more pronounced among insulin-treated patients than among non-insulin-treated diabetic patients, suggesting that the role of the gene polymorphism may become more manifest at later stages of the disease.

Our findings of decreased plasma MCP-1 levels in carriers of the $G$ allele are in agreement with data in patients with lupus nephritis [25]. In the present study, plasma MCP-1 levels were significantly and positively correlated with markers of the metabolic syndrome, such as insulin resistance, Type 2 diabetes, hypertension, obesity, WHR, high triglycerides and low HDL 
cholesterol, according to univariate analysis. These results are consistent with previous data in patients with Type IIa and IIb hyperlipoproteinaemia [35]. Moreover, we observed increased plasma MCP-1 levels in patients with Type 2 diabetes, corroborating previous data from the Orbofiban in Patients With Unstable Coronary Syndromes-Thrombolysis In Myocardial Infarction (OPUS-TIMI) 16 trial and from a cohort of women with glucose intolerance [36, 37]. Conversely, another study showed that insulin infusion results in decreased plasma MCP-1 levels in obese subjects [38].

Macrophage accumulation in human subcutaneous adipose tissue increases with increasing obesity and adipocyte size [6]. In obesity, infiltrating macrophages account for almost all TNF- $\alpha$ expression and a significant proportion of the expression of other inflammatory mediators in adipose tissue [6]. Interestingly, the epicardial adipose tissue of patients with $\mathrm{CAD}$ produces increased amounts of MCP-1, TNF- $\alpha$, IL-1 $\beta$, and IL-6 compared with epicardial adipose tissue of subjects without $\mathrm{CAD}$, suggesting that regional adipose tissue may be a source of atherogenic proinflammatory molecules [39].

The molecular mechanism by which the polymorphism regulates $M C P-1$ gene transcription is unclear. Although it is located in the distal regulatory region of the gene that contains two NF- $\mathrm{KB}$ binding sites essential for cytokine-stimulated gene transcription [24], the polymorphism does not alter the sequence of the $\mathrm{NF}-\kappa \mathrm{B}$ sites. Electrophoretic mobility shift assays have suggested that the binding site for an as yet unidentified transcription factor might be altered [22]. We propose that decreased MCP-1 expression in carriers of the $G$ allele may prevent the pathogenic vicious circle by which MCP-1 expression promotes macrophage accumulation in adipose tissue, TNF- $\alpha$ release by macrophages, TNF- $\alpha$-stimulated MCP- 1 expression and MCP-1-mediated antagonism of insulin activities in this tissue. Similarly, a single-nucleotide polymorphism in the promoter of the gene encoding resistin, an adipocyte-secreted hormone, has been linked to insulin resistance in humans [40].

In conclusion, we have reported, for the first time, that the $M C P-1 G-2518$ allele is significantly and negatively correlated with circulating MCP-1 levels, insulin resistance and Type 2 diabetes. Replication of the reported genetic associations in independent cohorts are needed to validate the role of the polymorphism in the development of insulin resistance.

Acknowledgements. This study was supported by the Teo Rossi di Montelera Foundation, (Lausanne, Switzerland) and the Swiss Cardiology Foundation. E. Simeoni, M. M. Hoffmann and B. R. Winkelmann contributed equally to this work. G. Vassalli and S. Fleury were the recipients of grants from the Swiss National Science Foundation (grant numbers 632058215 and 3100-64.834.01 respectively). B. O. Boehm was the recipient of a grant from the German Research Foundation (grant number SFB518).

\section{References}

1. Zimmet P, Alberti KG, Shaw J (2001) Global and societal implications of the diabetes epidemic. Nature 414:782-787

2. Grundy SM, Brewer HB, Cleeman JI, Smith SC, Lefant C (2004) Definition of metabolic syndrome. Circulation 109:433-438

3. Alexander CM, Landsman PB, Teutsch SM, Haffner SM (2003) NCEP-defined metabolic syndrome, diabetes, and prevalence of coronary heart disease among NHANES III participants age 50 years and older. Diabetes 52:1210-1214

4. Dandona P, Aljada A, Bandyopadhyay A (2004) Inflammation: the link between insulin resistance, obesity and diabetes. Trends Immunol 25:4-7

5. Wellen KE, Hotamisligil GS (2003) Obesity-induced inflammatory changes in adipose tissue. J Clin Invest 112:1785-1788

6. Weisberg SP, McCann D, Desai M, Rosenbaum M, Leibel RL, Ferrante AW Jr (2003) Obesity is associated with macrophage accumulation in adipose tissue. J Clin Invest 112:1796-1808

7. Xu H, Barnes GT, Yang Q et al. (2003) Chronic inflammation in fat plays a crucial role in the development of obesity-related insulin resistance. J Clin Invest 112:1821-1830

8. Uysal KT, Wiesbrock SM, Marino MW, Hotamisligil GS (1997) Protection from obesity-induced insulin resistance in mice lacking TNF- $\alpha$ function. Nature 389:610-614

9. Mohamed-Ali V, Goodrick S, Rawesh A et al. (1997) Subcutaneous adipose tissue releases interleukin-6, but not tumor necrosis factor-alpha, in vivo. J Clin Endocrinol Metab 82:4196-4200

10. Sartipy P, Loskutoff DJ (2003) Monocyte chemoattractant protein 1 in obesity and insulin resistance. Proc Natl Acad Sci USA 100:7265-7270

11. Takahashi K, Mizuarai S, Araki H et al. (2003) Adiposity elevates plasma MCP-1 levels leading to increased CD11bpositive monocytes in mice. J Biol Chem 278:4665446660

12. Yudkin JS, Kumari M, Humphries SE, Mohamed-Ali V (2000) Inflammation, obesity, stress and coronary heart disease: is interleukin-6 the link? Atherosclerosis 148:209214

13. Gerhardt CC, Romero IA, Cancello R, Camoin L, Strosberg AD (2001) Chemokines control fat accumulation and leptin secretion by cultured human adipocytes. Mol Cell Endocrinol 175:81-92

14. Juhan-Vague I, Alessi MC, Mavri A, Morange PE (2003) Plasminogen activator inhibitor-1, inflammation, obesity, insulin resistance and vascular risk. J Thromb Haemost $1: 1575-1579$

15. Yamauchi T, Kamon J, Waki $\mathrm{H}$ et al. (2001) The fatderived hormone adiponectin reverses insulin resistance associated with both lipoatrophy and obesity. Nat Med 7:941-946

16. Steppan CM, Bailey ST, Bhat S et al. (2001) The hormone resistin links obesity to diabetes. Nature 409:307-312

17. Bruun JM, Pedersen SB, Kristensen K, Richelsen B (2002) Effects of pro-inflammatory cytokines and chemokines on leptin production in human adipose tissue in vitro. Mol Cell Endocrinol 190:91-99

18. Rollins BJ (1996) Monocyte chemoattractant protein 1: a potential regulator of monocyte recruitment in inflammatory disease. Mol Med Today 2:198-204

19. Takaishi H, Taniguchi T, Takahashi A, Ishikawa Y, Yokoyama M (2003) High glucose accelerates MCP-1 production via p38 MAPK in vascular endothelial cells. Biochem Biophys Res Comm 305:122-128 
20. Shanmugam N, Reddy MA, Guha M, Natarajan R (2003) High glucose-induced expression of proinflammatory cytokine and chemokine genes in monocytic cells. Diabetes $1256-1264$

21. Sartipy P, Loskutoff DJ (2003) Expression profiling identifies genes that continue to respond to insulin in adipocytes made insulin-resistant by treatment with tumor necrosis factor-alpha. J Biol Chem 278:52298-52306

22. Rovin BH, Lu L, Saxena R (1999) A novel polymorphism in the $M C P-1$ gene regulatory region that influences MCP-1 expression. Biochem Bioph Res Comm 259:344348

23. Sylvester I, Suffredini AF, Boujoukos AJ et al. (1993) Neutrophil attractant protein-1 and monocyte chemoattractant protein-1 in human serum. Effects of intravenous lipopolysaccharide on free attractants, specific IgG autoantibodies and immune complexes. J Immunol 151:32923298

24. Ueda A, Okuda K, Ohno S, Shirai A, Igarashi T, Matsunaga K (1994) NF-kappa B and Sp1 regulate transcription of the human monocyte chemoattractant protein-1 gene. J Immunol 153:2052-2063

25. Kim HL, Lee DS, Yang SH et al. (2002) The polymorphism of monocyte chemoattractant protein-1 is associated with the renal disease of SLE. Am J Kidney Dis 40:1146-1152

26. Muhlbauer M, Bosserhoff AK, Hartmann A et al. (2003) A novel $M C P-1$ gene polymorphism is associated with hepatic MCP-1 expression and severity of HCV-related liver disease. Gastroenterology 125:1085-1093

27. Szalai C, Duba J, Prohatzka Z et al. (2001) Involvement of polymorphisms in the chemokine system in the susceptibility for coronary artery disease (CAD). Coincidence of elevated $\mathrm{Lp}(\mathrm{a})$ and $M C P-1-2518 \mathrm{G} / \mathrm{G}$ genotype in CAD patients. Atherosclerosis 158:233-239

28. Szalai C, Kozma GT, Nagy A et al. (2001) Polymorphism in the gene regulatory region of $M C P-1$ is associated with asthma susceptibility and severity. J Allergy Clin Immunol 108:375-381

29. Winkelmann BR, März W, Boehm BO et al.; LURIC Study Group (LUdwigshafen RIsk and Cardiovascular health) (2001) Rationale and design of the LURIC study-a resource for functional genomics, pharmacogenomics and long-term prognosis of cardiovascular disease. Pharmacogenomics 2 [Suppl 1]:S9-S73
30. Nakai Y, Fukushima M, Nakaishi S et al. (2002) The threshold value for insulin resistance on homeostasis model assessment of insulin sensitivity. Diabet Med 19:344-348

31. Alberti KG, Zimmet PZ (1998) Definition, diagnosis and classification of diabetes mellitus and its complications. Part 1: diagnosis and classification of diabetes mellitus provisional report of a WHO consultation. Diabet Med 15:539-553

32. Expert Committee on the Diagnosis and Classification of Diabetes Mellitus (2002) Report of the expert committee on the diagnosis and classification of diabetes mellitus [from the American Diabetes Association, ADA]. Diabetes Care 25 [Suppl 1]:S1-S20

33. World Health Organization (1999) Definition, diagnosis and classification of diabetes mellitus and its complications. Report of a WHO consultation. Part 1 Diagnosis and classification of diabetes mellitus WHO/NCD/NCS/99. World Health Organization, Geneva

34. Taubert G, Winkelmann BR, Schleiffer T et al. (2003) Prevalence, predictors, and consequences of unrecognized diabetes mellitus in 3266 patients scheduled for coronary angiography. Am Heart J 145:285-291

35. Kowalski J, Okopien B, Madej A et al. (2001) Level of sICAM-1, sVCAM-1 and MCP-1 in patients with hyperlipoproteinemia IIa and -IIb. Int J Clin Pharmacol Ther 39:48-52

36. Lemos JA de, Morrow DA, Sabatine MS et al. (2003) Association between plasma levels of monocyte chemoattractant protein-1 and long-term clinical outcomes with acute coronary syndromes. Circulation 107:690-695

37. Piemonti L, Calori G, Mercalli A et al. (2003) Fasting plasma leptin, tumor necrosis factor- $\alpha$ receptor 2, and monocyte chemoattractant protein 1 concentration in a population of glucose-tolerant and glucose intolerant women. Diabetes Care 26:2883-2889

38. Dandona P, Aljada A, Mohanty P et al. (2001) Insulin inhibits intranuclear nuclear factor kappaB and stimulates IkappaB in mononuclear cells in obese subjects: evidence for an anti-inflammatory effect? J Clin Endocrinol Metab $86: 3257-3265$

39. Mazurek T, Zhang L, Zalewski A et al. (2003) Human epicardial adipose tissue is a source of inflammatory mediators. Circulation 108:2460-2466

40. Smith SR, Bai F, Charbonneau C, Janderova L, Argyropoulos G (2003) A promoter genotype and oxidative stress potentially link resistin to human insulin resistance. Diabetes 52:1611-1618 